\title{
Fast and Extensive Model Based Project Plan Building in Nuclear Industry
}

\author{
Christian Marie, Gilles Beuzelin, Samuel Boutin and Eric Nicole
}

\begin{abstract}
Areva investigated a Model Based approach for setting up the Work Breakdown Structure of a nuclear plant project performed in collaboration with other key industrial partners of the energy domain.
\end{abstract}

Problems to be solved included:

- Manage collaboration between several industrial partners having their own processes, methods and approaches.

- Generate the Work Breakdown Structure (WBS) and Work Packages Descriptions (WPD) for the project.

Modeling benefits were:

- Convergence on a set of generic processes to be applied together with associated standard document types: specifications, justification, design, validation... documents.

- Quick production of WBS from the Product Breakdown Structure (PBS) (e.g. we issued a PBS with 100 items and got a WBS with more than 100 Work Packages and 1000 documents and items) as a basis for cost analysis and planning.

- An objective and neutral support for project plan enabling more efficient collaboration.

C. Marie

AREVA TA, Route de Saint Aubin, 91190 Villiers-le-Bâcle, France

e-mail: Christian.marie@areva.com

G. Beuzelin

AREVA, Tour AREVA, 1, place Jean Millier, 92400 Courbevoie, France

e-mail: gilles.beuzelin@areva.com

S. Boutin · E. Nicole (汭

Knowledge Inside, 7B rue Jean Mermoz, 78000 Versailles, France

e-mail: eric.nicole.bp@k-inside.com

S. Boutin

e-mail: samuel.boutin@k-inside.com

G. Fanmuy et al. (eds.), Complex Systems Design \& Management,

DOI 10.1007/978-3-319-49103-5_25 